\title{
Decline of Jakar sheep population in pastoral communities of Bhutan: A consequence of diminishing utility, alternate income opportunities and increasing challenges
}

\author{
Jigme Dorji , Sonam Tamang and Tashi Yangzome Dorji
}

\begin{abstract}
Jakar sheep population in Bhutan is declining at unprecedented rate (44.4\% per annum), and current population is little over 1,700. This study attempts to understand the current status of Jakar sheep and investigate the causes and drivers behind the rapid decline in population. The utility of sheep and wool in particular for clothing by herders is also declining. Sheep farming is increasingly becoming less attractive in face of alternative income sources and opportunities such as sale of potatoes and cordyceps ("caterpillar fungus") in the pastoral communities. The average monetary returns from sheep to annual herd income constitute less than $0.26 \%$ in sites with large alternate income sources. Wool processing and product-making continues to employ traditional, labour-intensive and time-consuming tools. Further, wildlife depredation (77\%), skin disease (54\%) and farm labour shortages (10\%) continue to challenge Jakar sheep farming. Therefore, immediate interventions targeted to address the issues through incentive schemes in niche production development, use of labour-saving devices and marketing to generate monetary benefits including compensation to animal loss are recommended. In addition, the initiation and strengthening of ex situ conservation programs for sustainable utilization of its genetic resources is highly recommended.
\end{abstract}

Keywords: Jakar sheep, Challenges, Conservation, Sustainable use, Bhutan

\section{Introduction}

The roles of diverse animal genetic resources for food and fibre production, livelihood, ecosystem services and socio-culture are well recognized. In addition, they have a crucial role in adaptation to the emerging challenges and issues related to climate change in animal-based food production (FAO 2015). Globally, such diverse traditional breeds are at threat and losses are unprecedented rate. Jakar sheep is one of the rapidly declining livestock breeds in Bhutan. The breed in the past was an important livestock species in addition to yak and horse in northern alpine pastoral communities of Bhutan. They are primarily

\footnotetext{
* Correspondence: jigmedorjik@gmail.com

National Biodiversity Centre, Ministry of Agriculture and Forests, Serbithang, Thimphu, Bhutan
}

kept for wool and a species associated with annual ritualistic sacrificial animals in some communities.

Jakar sheep is characterized by a small body size and weighs about $34 \mathrm{~kg}$ (Dorji et al. 2008) (Figure 1). They are predominantly black coated $(80 \%)$ (Tamang 2015) and produce medium-fine wool (Kishore and Gopikrishna 2011). The wool is processed to a variety of traditional woolen garments. It is believed that Jakar sheep is introduced from a place called Tshona in south east Tibet (China) during the seventh century a.d. (Dorji et al. 2008). Since then, it has evolved and adapted to the cold, harsh and rugged environment in alpine areas of the country and established as a prominent breed in the country. However, they are currently found only in highaltitude areas: Chhoekhor, Chummey and Phobji subdistricts of the country. 


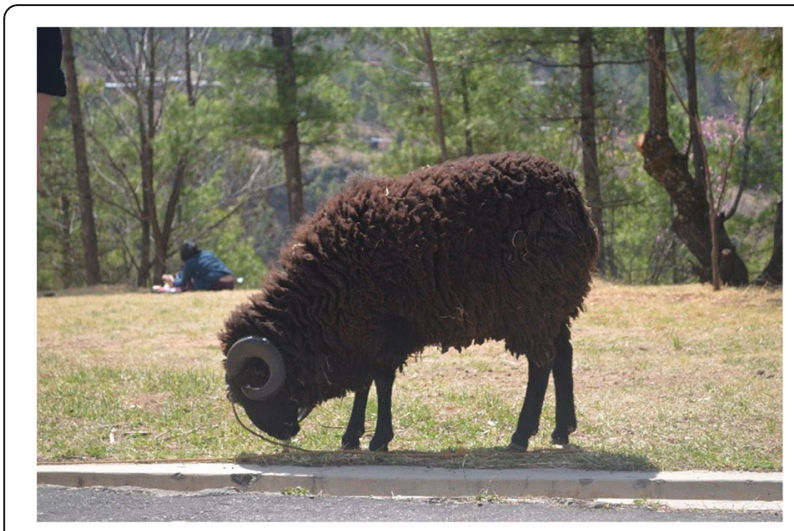

Figure 1 Jakar sheep ram

In this view, this study was designed to understand the current status of Jakar sheep population and identify drivers/causes for its decline. The findings of the study were expected to help in devising appropriate measures to address the issues, stablize population and promote sustainable utilization of the breed.

\section{Study area}

The study sites (Figure 2) were selected based on existence of Jakar sheep population and the history of their importance in the livelihood of the communities: Dhur in Chhoekhor, Chungphel in Chummey and Phobji subblocks of Bhutan.

\section{Methods}

In total, 68 Jakar sheep farmers (26 males and 42 females) were interviewed using semi-structured questionnaires containing a mix of open and closed-end questions to capture current status of sheep (flock size, composition and population trends), income and key issues. Further, 24 farmers actively involved in wool processing and/or product development were chosen as key informants. The data was entered in Statistical Package for Social Science 23 by IBM Corp (2013) and performed descriptive analyses, parametric and nonparametric tests. The yearly statistical data from Department of Livestock, Bhutan, over the past decade was used for the changes of Jakar sheep population.

\section{Results}

\section{Household utility of Jakar sheep}

Jakar sheep continue to be primarily kept for wool by all of the respondents. The average wool yield was $448.66 \pm$ $109.4 \mathrm{~g}$ per animal per shearing and generally shorn twice a year. The skin diseases reduced the wool yield among 54\% of the herders. The manure is emerging as an important utility among sedentary sheep farmers in Chungphel and Phobji (80\%), who also grow a few seasonal crops. The previously reported practice of ritualistic sacrifice of Jakar sheep was nonexistent in the current study.

\section{Age and gender of Jakar sheep farmers}

Figure 3 represents the engagement of different age groups in sheep farming. The number of farmers engaged under different age categories was not significantly different, although involvement of the old age range was the lowest. Overall, more women (twice as many as men) were engaged into sheep farming. Although women were
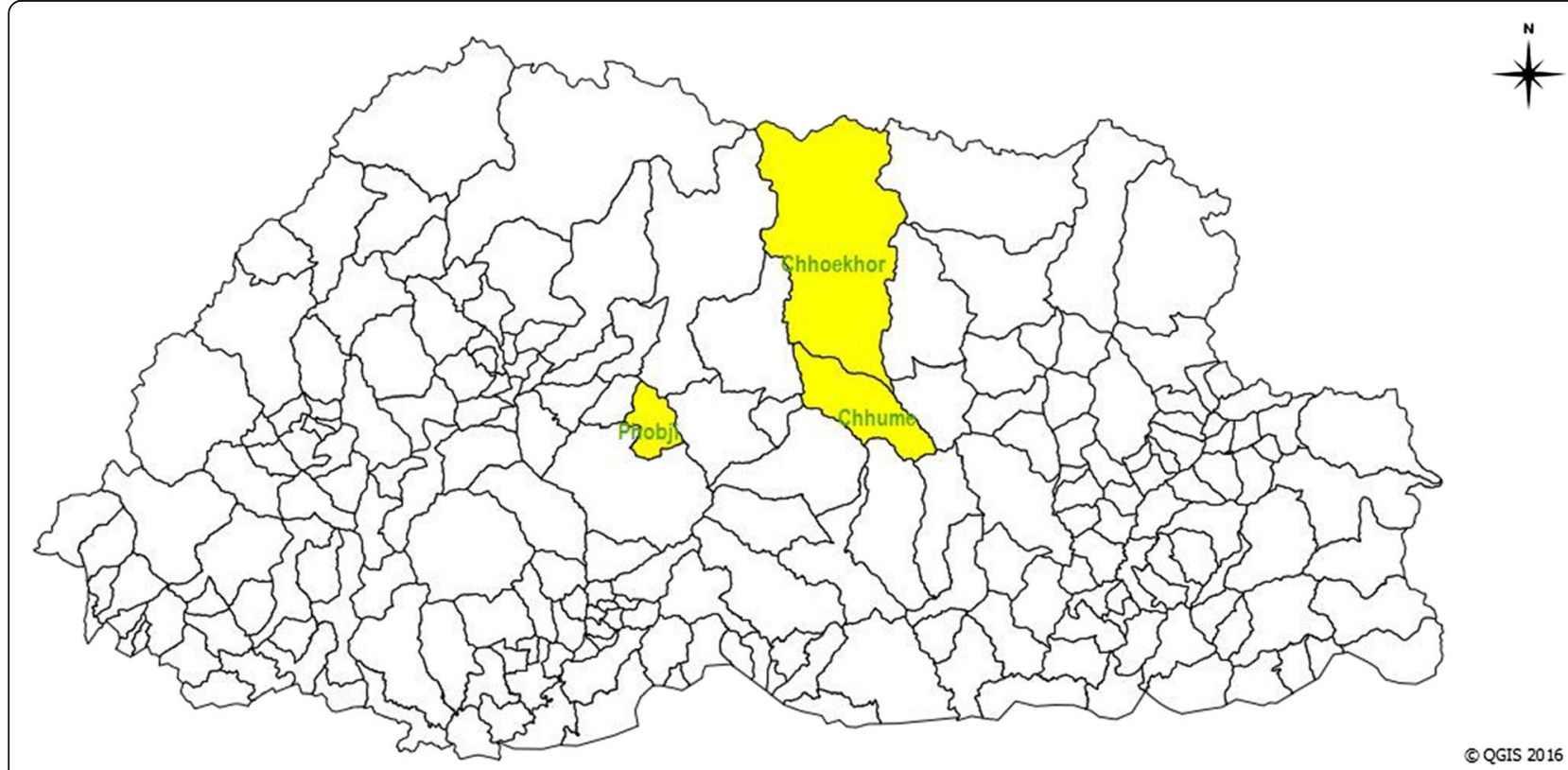

Figure 2 Jakar sheep rearing sites and study areas in Bhutan 


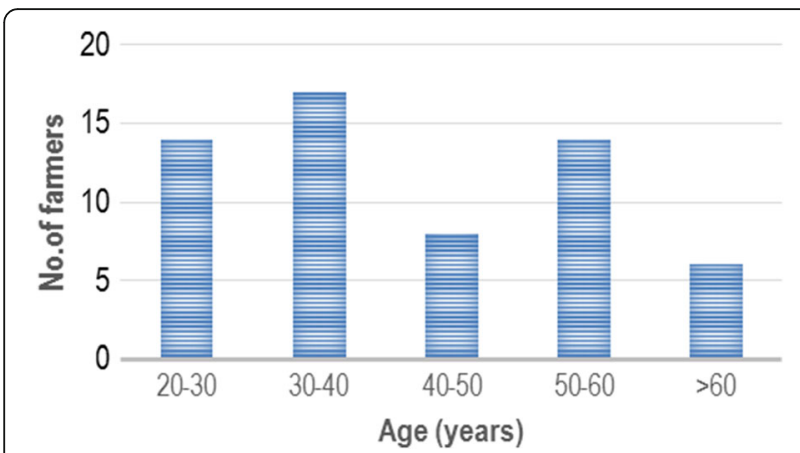

Figure 3 Age range of informants

generally involved in product processing, there was no association between the gender and type of involvement in sheep farming.

\section{Jakar sheep management}

Unlike in the past, Jakar sheep farming is increasingly becoming sedentary (57\%) followed by sedentary with summer migration (38\%). True migration (year-long) along with the yaks is limited to Dhur, representing about 5\% of the respondents. Sheep farmers in Chungphel had abandoned yak farming in the recent past and switched to sedentary sheep management. The sedentary management is characterized by letting out animals to graze on natural pasture during the day and collected to the homestead by evening. About $50 \%$ of respondents in Phobji practise a unique twomonth long migration in a year specifically in June to July, along with yaks.

\section{Sheep population, composition and trend}

Jakar sheep population and its composition in the study areas are presented in Table 1 . The estimated total population of Jakar sheep at the sites is 1,737. Dhur had the highest average flock size followed by Phobji. However, Phobji possessed the highest population of Jakar sheep. The proportion of breeding male to female was 1:9. The castrates were thrice the number of adult breeding male population because the castrates are considered to produce more wool than uncastrated adults.

The majority of the respondents (92\%) indicated that the sheep population has declined over the years and specifically the individual flock sizes declined at an average of $54.67 \%$ during the last five years.

\section{Income from sheep}

Table 2 presents some of the major income sources of the sheep farmers and the relative proportion of monetary benefits. The sale of potatoes and cordyceps represented burgeoning income alternatives to sheep farmers. Potatoes contributed over $97 \%$ to household income for farmers in Phobji (average annual household income (AAHI) of $\mathrm{Nu}$. 214,000). The lack of income from sheep farming was cited by one fifth of respondents for the purposive reduction of flock size in their herds.

In contrast, in Chungphel, with a lack of alternative income sources, the sale of wool products often targeted for tourists continued to be the most important source of income $(\mathrm{Nu} .28,000)$ for the sheep farmers. The sale of milk and milk products from yak and cattle contributed up to $17.7 \%$ (Dhur) and $2.47 \%$ (Phobji) of household's income and livelihoods. Unlike other sources, herders counted cattle and yaks as more reliable source of income due to their consistency.

\section{Major challenges in sheep farming}

Depredation of sheep by wildlife was the most common challenge (77\%) among the respondents (Figure 4). The predators included bear, leopard, wild dogs and stray dogs. The most incidences of depredation occurred during free ranging on pastures where the animals are often unattended.

Other challenges included lack of or inadequate processing skills (78\%) and labour shortages (1:10), and for this reason, only about $38 \%$ of respondents processed wool into products while others sold raw wool. Wool processing and making wool product is limited to traditional products and employs traditional processing techniques and devices.

Table 1 Sheep population, composition and sheep holding in study site

\begin{tabular}{|c|c|c|c|c|c|c|c|c|c|}
\hline \multirow[t]{3}{*}{ Site } & \multirow[t]{3}{*}{$N^{\circ}$} & \multicolumn{3}{|l|}{ Male } & \multicolumn{2}{|c|}{ Female } & \multirow[t]{3}{*}{ Total nos. } & \multirow[t]{3}{*}{ Flock size } & \multirow[t]{3}{*}{ Decline $^{a}(\%)$} \\
\hline & & \multirow[t]{2}{*}{ Lamb } & \multicolumn{2}{|l|}{ Adult } & \multirow[t]{2}{*}{ Lamb } & \multirow[t]{2}{*}{ Adult } & & & \\
\hline & & & Breeding & $\overline{\text { Castrate }}$ & & & & & \\
\hline 1. Chungphel (Chhumey) & 9 & 17 & 12 & 14 & 28 & 58 & 129 & 14 & 61.67 \\
\hline 2. Dhur (Chhoekhor) & 3 & 14 & 9 & 51 & 13 & 39 & 126 & 42 & 61.00 \\
\hline 3. Phobji & 55 & 96 & 95 & 261 & 196 & 834 & 1,482 & 27 & 41.34 \\
\hline Total & 67 & 127 & & & & & 1737 & & \\
\hline
\end{tabular}

$\mathrm{N}^{\circ}$, No. of households

${ }^{\mathrm{a}}$ Decline during last five years (2010 to 2015) 
Table 2 Average annual household income from various sources for sheep farmers

\begin{tabular}{lllll}
\hline Site & Income sources & No. HH & AAHI (Nu.) & Proportion ${ }^{\text {a }}$ (\%) \\
\hline Chungphel (Chhumey) & Sale of wool and wool products & 6 & 28,000 & 100.00 \\
Dhur (Chhoekhor) & Sale of cheese and butter (yak) & 3 & 48,000 & 223,000 \\
& Sale of cordyceps & 3 & 0 & 17.71 \\
& Sale of wool and wool products & & 12,681 & 0.00 \\
Phobji & Sale of milk products (yak/cattle) & 21 & 1,124 & 2.47 \\
& Sale of wool and wool products & 25 & 4.26 & 9.26 \\
\hline
\end{tabular}

No. $\mathrm{HH}$, Number of households; AAHI, Average annual household income

a Relative to $\mathrm{AAHI} ; * 1 \mathrm{USD}=$ Approximately $68 \mathrm{Nu}$

Wool product processing is labour intensive and employed traditional tools: Thochu, Chanab, Bayshay, Yoke, Kheel, Chafang, Thakshing, Thritha, Pangtha and Pubrat in all the three sites (Figure 5). The wool carding and spinning was the most time-consuming (four to six days per kilogramme of raw wool) steps in wool processing. In addition, weaving is also another time-consuming process. For instance, the weaving of a traditional dress (Gho and Kira) besides wool processing required at least five and four days, respectively.

\section{Discussion}

The population of Jakar sheep in the country declined from estimated 11,000 in 2003 (Dorji et al. 2003) to less than 2,000 (DoL 2014) over a decade corresponding to about $80 \%$ decline. The current rate of decline, if unchecked, is likely to result in breed extinction within next five years. Further, the comparison of the breed distribution reveals a drastic shrinkage in distribution from over 11 sub-districts to three sites in the current study (Chhoekhor, Chummey and Phobji). The current population and ratio of breeding males to females according to FAO risk classification system (FAO 2015) is categorized as breed 'not at risk'. However, the rapid rate of decline in population warrants immediate attention and interventions.

Some of the drivers attributing to the decline in Jakar sheep population are as follows.

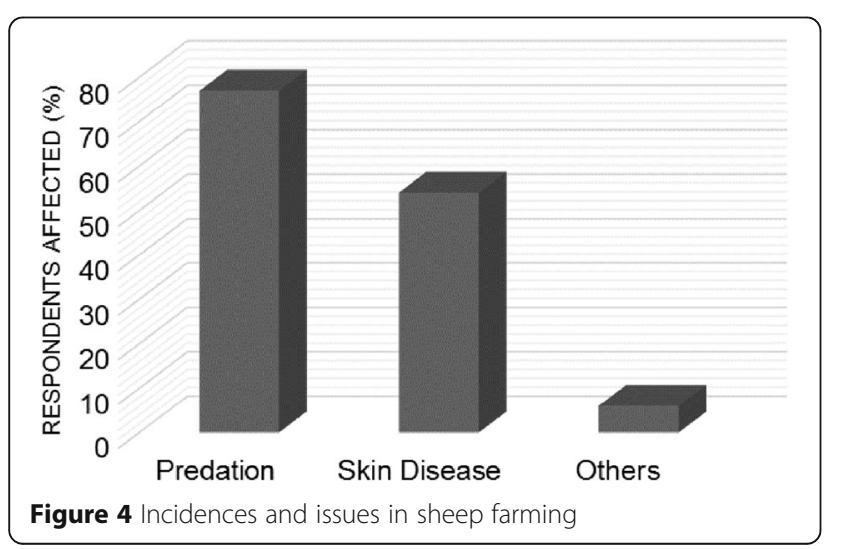

\section{Diminishing utility of Jakar sheep}

The objective of sheep farming to produce wool and household clothing to protect against harsh winters has become obsolete in the light of the rapid socioeconomic development of the country. Ready-made garments (Figure 6) are available for sale in the areas and increasingly preferred for their cheaper costs. The costs of traditional wool products are exorbitantly higher due to labour (minimum daily wage rate of $\mathrm{Nu}$. 211) and more number of days required. Further, the lesser common use of Jakar sheep in ritualistic offering is no longer practised by the communities and substituted with offering of eggs or potatoes. The Jakar sheep do not have meat utility as sheep slaughter is considered a religious taboo among the communities. Thus, Jakar sheep is surviving with a diminishing utility of wool and herders favouring the reduction in flock sizes.

\section{Relatively low or no income from sheep farming}

The road accessibility in many areas has led to adoption and expansion of potato cultivation with a lag period of only a few years (Roder 2004). Potatoes are one of the important cash crops for areas above 2,500 masl. Wangduephodrang district with mostly Phobji is the highest potato production area in the country (DoA 2014), and accounted up to $28 \%$ of potato export volume (Roder et al. 2007).

The sale of cordyceps accounted for about $82 \%$ of AAHI $(\mathrm{Nu} .223,000)$ in Dhur. The annual income from cordyceps $(\mathrm{Nu} .23,000)$ for yak herders (Wangchuk and Wangdi 2015) is lower than the current study. The price of cordyceps has steadily increased by over ten folds from 2004 (legalization of cordyceps collection) to 2014 (DAMC 2014), thereby attracting more herder collectors each year. The alternative income sources provide livelihood improvement and economic resilience but when disproportionately high incomes such as from cordyceps, this can negatively impact other pastoral species such as yak farming in Bhutan (Wangchuk and Wangdi 2015). This also suggests that cordyceps as an alternate income source also have negative 


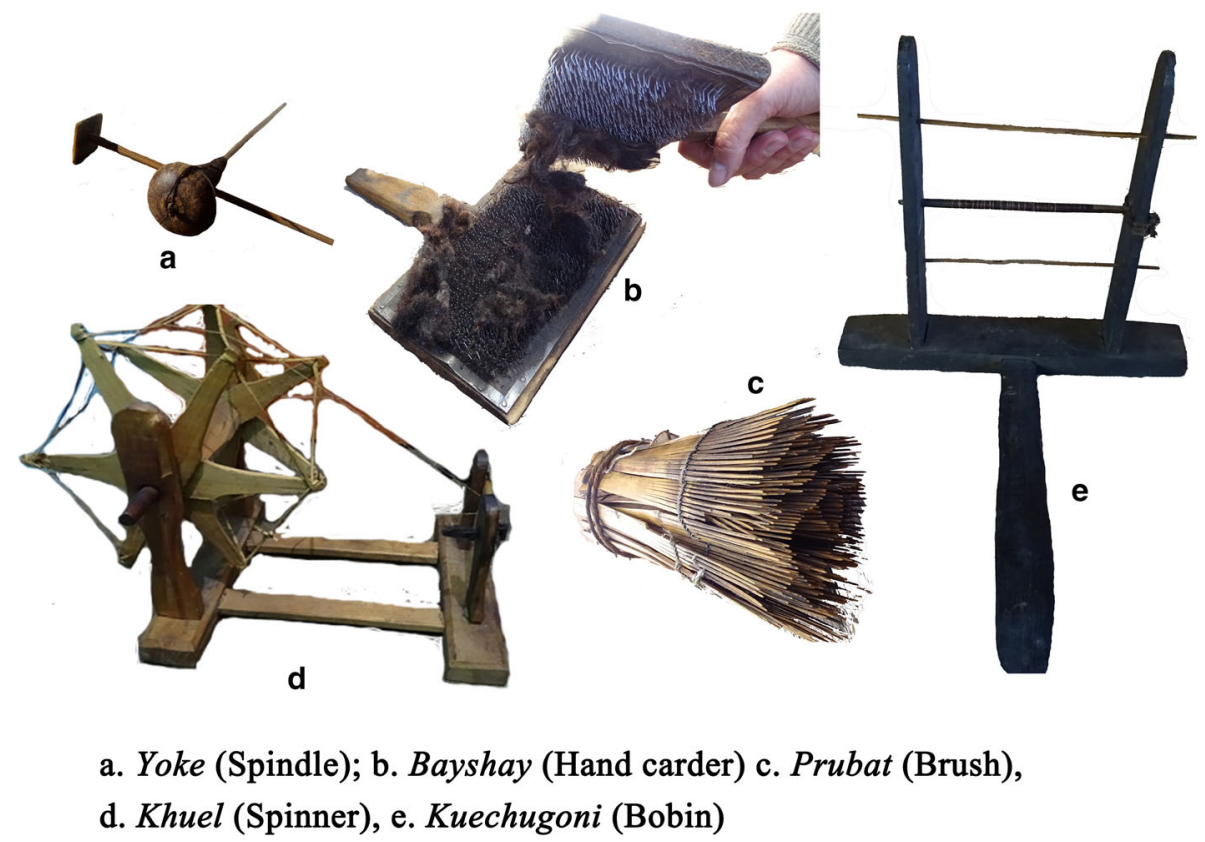

Figure $\mathbf{5}$ Traditional wool processing tools

impact similar effect on sheep farming in Phobji and Dhur sites.

\section{Dying skill of wool processing and products making}

This study found that little more than third of the respondents are involved in wool processing and product making. The cessation of the activity was attributed to highly inter-related factors such as farm labour shortage and lack of skills which was further discouraged by a low monetary benefit. Cessation was also in part due to tedious steps involved in wool processing and making products. Except for the Chummey farmers, other sites continued to make traditional products for sale in the locality.

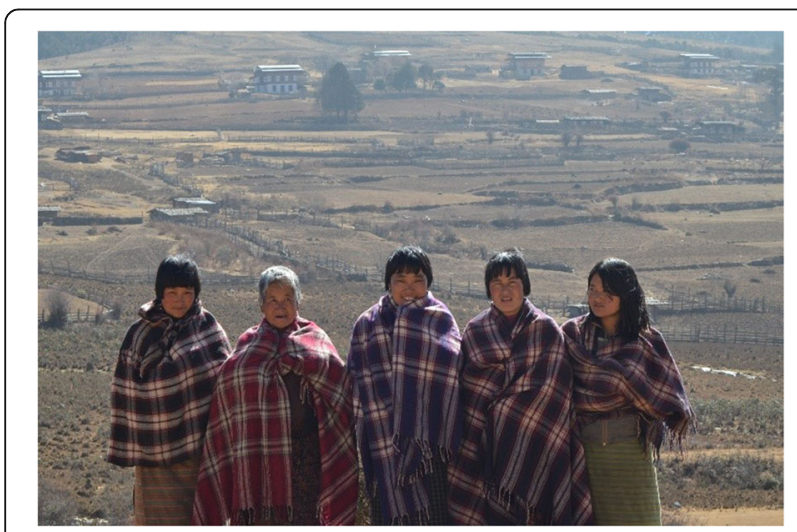

Figure 6 Jakar sheep farmers cladded in imported and readymade shawls
Loss of animals to wildlife depredation

Sheep are the most susceptible livestock species to depredation ( $\mathrm{Li}$ et al. 2015). Depredation of livestock is common in Bhutan (Sangay and Karl Vernes 2008) and a major constraint in yak farming among the pastoralists (Wangchuk and Wangdi 2015). While the direct contribution of depredation to the decline in Jakar sheep population is minimal, it indirectly encouraged farmers to reduce the flock sizes for optimum sizes.

\section{Conclusions}

There is only a near critical population of Jakar sheep in the country, and declining at rapid rate. Sheep farming has lost its importance due to no further need to produce clothing from the herd; minimal or no income; and other challenges dissuading sheep farming. Depredation by wildlife, skin diseases, feed shortages and labour shortages continue to impede sheep farming and has led to reduction in flock size or farmers giving up sheep farming.

\section{Recommendations}

In view of the rapidly declining Jakar sheep population in the country, the promotion of conservation and sustainable utilization of the breed warrants immediate intervention through the following recommendations:

- In situ conservation and utilization by addressing the issues and challenges and making sheep farming a viable economic enterprise for sheep farmers 
- Income generation through development of niche wool products, product diversification and marketing in addition to capacity building of farmers

- Encouraging the use of labour-saving devices in wool processing and product development to moderate the hard labour requirement and also to address farm labour shortages

- Initiation of ex situ conservation of the breed in form of semen and nucleus farms to complement field interventions

\section{Abbreviations}

AAHI: Average annual household income; DAMC: Department of Agricultural Marketing and Cooperatives; DoA: Department of Agriculture; DoL: Department of Livestock; FAO: Food and Agriculture Organization; masl: Meters above sea-level; Nu.: Ngultrum

\section{Acknowledgements}

The authors would like to thank the District Livestock Officers and Geog Livestock Extension Officers of the study sites for coordinating the visit for data collection. We would also like to thank the reviewers for their valuable feedback and comments in bringing the article to its current status.

\section{Funding}

This study was partially funded by Bhutan Trust Fund for Environment Conservation (BTFEC) and Royal Government of Bhutan.

\section{Availability of data and materials}

The dataset supporting the conclusions of this article will be available in the offline data repository of National Biodiversity Centre repository and may be available on request at info@nbc.gov.bt. Other statistical data are all available online at hyperlinks provided in the reference section.

\section{Authors' contributions}

JD was involved in the conception and design of the study, data analysis and interpretation, drafting and revising the manuscript. ST contributed to the study conception, data collection and drafting of manuscript. TYD contributed to the study conception and design, analyses and interpretation of data and revision of the manuscript. All authors read and approved the final manuscript.

\section{Authors' information}

Jigme Dorji (JD) is a Deputy Chief Biodiversity Officer under Animal Genetic Resources Program, National Biodiversity Centre. Sonam Tamang (ST) is the Principal Biodiversity Officer in Animal Genetic Resources Program, National Biodiversity Centre. Tashi Y. Dorji (TYD) is the Program Director of the National Biodiversity Centre, Ministry of Agriculture and Forests. Royal Government of Bhutan.

\section{Competing interests}

The authors declare that they have no competing interests.

Received: 26 November 2016 Accepted: 3 February 2017

Published online: 21 February 2017

\section{References}

DAMC. 2014. Cordyceps marketing report for the year 2014. edited by Department of Agricultural Marketting \& Cooperatives (DAMC). Thimphu, Bhutan: Ministry of Agriculture and Forests.

DoA 2014. Agriculture statistics 2014. edited by Department of Agriculture (DoA), Ministry of Agriculture and Forests. Thimphu, Bhutan.

DoL. 2014. Livestock statistics 2014. edited by Department of Livestock and Ministry of Agriculture and Forests. Thimphu, Bhutan.

Dorji, T., G. Tshering, T. Wangchuk, J.E.O. Rege, and O. Hannote. 2003. Indigenous sheep genetic resources and management in Bhutan. Animal Genetic Resources Information 33: 81-91.
Dorji, T., G. Tshering, D.L. Sherpa, and N.B. Tamang. 2008. Sheep. In Animal genetic resources of Bhutan, ed. Tashi Y. Dorji, O. Tshewang, and Tamang Sonam. Serbithang, Thimphu Bhutan: National Biodiversity Centre, Ministry of Agriculture and Forests.

FAO. 2015. The second state of world animal genetic resources. Rome, Italy: United Nations Organization.

IBM Corp. Released 2013. IBM SPSS Statistics for Windows, Version 22.0. Armonk, NY: IBM Corp.

Kishore, K., and Gopikrishna. 2011. Remunerative markets for Bhutanese sheep and yak wool and by-products - prospect for sustainable livelihoods \& conservation. A consultancy report. Serbithang, Thimphu, Bhutan: National Biodiversity Centre, Ministry of Agriculture and Forests.

Li, Chunlin, Jiang Zhigang, Chunwang Li, Songhua Tang, Feng Li, Zhenhua Luo, Xiaoge Ping, Zhao Liu, Jing Chen, and Hongxia Fang. 2015. Livestock depredations and attitudes of local pastoralists toward carnivores in the Qinghai Lake Region, China. Wildlife Biology 21(4): 204-212. doi:10.2981/wlb. 00083.

Roder, Walter. 2004. Are mountain farmers slow to adopt new technologies? Mountain Research and Development 24(2): 114-118. DOl: http://dx.doi.org/10. 1659/0276-4741(2004)024[0114:AMFSTA]2.0.CO;2, URL: http://www.bioone. org/doi/full/10.1659/0276-4741\%282004\%29024\%5B0114\%3AAMFSTA\%5D2.0. CO\%3B2.

Roder, W., Nidup, K. and Wangdi, S. 2007. Marketing of Bhutanese Potato. In Experiences, challenges and opportunities. Bhutan Potato Development Program. available at http://cipotato.org/wp-content/uploads/2015/07/ 003850.pdf.

Sangay, Tiger, and Karl Vernes. 2008. Human-wildlife conflict in the Kingdom of Bhutan: Patterns of livestock predation by large mammalian carnivores. Biological Conservation 141(5): 1272-1282. doi:http://dx.doi.org/10.1016/j. biocon.2008.02.027

Tamang, S. 2015. Community consultation meeting and baseline information of Jakar sheep for conservation and sustainable use in high altitude northern areas of Bhutan. Serbithang. Thimphu, Bhutan: National Biodiversity Centre.

Wangchuk, Kesang, and Jigme Wangdi. 2015. Mountain pastoralism in transition: Consequences of legalizing cordyceps collection on yak farming practices in Bhutan. Pastoralism 5(1): 4. doi:10.1186/s13570-015-0025-x.

\section{Submit your manuscript to a SpringerOpen ${ }^{\mathcal{O}}$ journal and benefit from:}

- Convenient online submission

- Rigorous peer review

- Immediate publication on acceptance

- Open access: articles freely available online

- High visibility within the field

- Retaining the copyright to your article

Submit your next manuscript at springeropen.com 